The University of San Francisco

USF Scholarship: a digital repository@ Gleeson Library |

Geschke Center

1998

\title{
Dissociation Energies of the Ga2, In2, and GaIn Molecules
}

G Balducci

G Gigli

Giovanni Meloni

Follow this and additional works at: http://repository.usfca.edu/chem_fac

Part of the Chemistry Commons

\section{Recommended Citation}

Balducci, G., \& Gigli, G. (1998). Dissociation energies of the Ga[sub 2], In[sub 2], and Galn molecules. Journal Of Chemical Physics, 109(11), 4384.

This Article is brought to you for free and open access by the Chemistry at USF Scholarship: a digital repository @ Gleeson Library| Geschke Center. It has been accepted for inclusion in Chemistry Faculty Publications by an authorized administrator of USF Scholarship: a digital repository @ Gleeson Library | Geschke Center. For more information, please contact repository@usfca.edu. 


\title{
Dissociation energies of the $\mathrm{Ga}_{2}, \mathrm{In}_{2}$, and Galn molecules
}

\author{
G. Balducci, G. Gigli, and G. Meloni \\ Dipartimento di Chimica, Università di Roma 'La Sapienza,' I-00185 Roma, Italy
}

(Received 26 Januar y 1998; accepted 9 June 1998)

\begin{abstract}
The group III metal dimers $\mathrm{Ga}_{2}$ and $\mathrm{In}_{2}$ and the newly identified intermetallic molecule GaIn were investigated in a Knudsen cell-mass spectrometric study of the vapors over gallium-indium alloys. From the all-gas equilibria analyzed by the second-law and third-law methods the following dissociation energies were derived; $D_{0}^{0}\left(\mathrm{Ga}_{2}\right)=110.8 \pm 4.9 \mathrm{~kJ} \mathrm{~mol}^{-1}, D_{0}^{0}\left(\mathrm{In}_{2}\right)=74.4 \pm 5.7 \mathrm{~kJ} \mathrm{~mol}^{-1}$, $D_{0}^{0}(\mathrm{GaIn})=90.7 \pm 3.7 \mathrm{~kJ} \mathrm{~mol}^{-1}$. The value here measured for the dissociation energy of $\mathrm{In}_{2}$ is discussed and compared with a previous experimental determination and with the results of more recent theoretical investigations. (C) 1998 American Institute of Physics. [S0021-9606(98)00435-8]
\end{abstract}

\section{INTRODUCTION}

Great interest has been focused over the past years on the study of the electronic and spectroscopic properties of small metal clusters. The objective of the intense theoretical and experimental investigations of diatomics and triatomics of transition metal atoms, also aided by advances in spectroscopic and computational techniques, is ultimately an understanding of the nature of bonding in these compounds. In view of this interest currently expressed, some theoretical and also experimental investigations ${ }^{1-3}$ of the heavier main group III dimers $\mathrm{Ga}_{2}, \mathrm{In}_{2}, \mathrm{Tl}_{2}$ recently were added to the early studies on the electronic structures and dissociation energies. $^{4}$

However, accurate determinations of the dissociation energies are still scarce and far from being definitely accomplished for the above dimers and apparently completely lacking for the heteronuclear diatomics of the intergroup IIIA metals mostly as a consequence of experimental difficulties.

We have undertaken experimental investigations by an equilibrium technique such as Knudsen cell mass spectrometry (KC-MS) aimed first at the identification and determination of dissociation energy of the heteronuclear diatomics of the intergroup IIIA and, also at the assessment of those homonuclear diatomics scarcely studied making use in data evaluation of the more recent theoretical and spectroscopic characterization made available. In particular, the results here presented concern the first identification and thermochemical characterization of the GaIn molecule and, jointly, the redetermination of dissociation energy for the $\mathrm{Ga}_{2}$ and $\mathrm{In}_{2}$ dimers based on extensive equilibrium measurements and on a new set of critically evaluated thermal functions of the species under study.

\section{EXPERIMENT}

All equilibrium measurements were made with a magnetic-focusing mass spectrometer coupled with a Knudsen cell molecular source assembly, a classical but still most versatile and almost invaluable tool at disposal for this kind of investigation. The instrument and experimental procedure have been described elsewhere. ${ }^{5}$ A high-purity, high-density graphite Knudsen cell with $0.5 \mathrm{~mm}$ orifice diameter and 0.7
Clausing factor was used throughout the experiments. The cell was heated by radiation by a tungsten coil resistor and the temperatures were measured with an optical pyrometer previously calibrated against a standard NBS certified lamp by sighting on a blackbody hole in the bottom of the cell. Calibration of the pyrometer was also checked in situ at the melting point of silver and gold in the course of various vaporization runs. The molecular beam effusing from the cell was ionized with $70 \mathrm{~V}$ electrons, the electron emission current being generally set at $1.0 \mathrm{~mA}$.

\section{RESULTS}

\section{A. Identification of ions}

Equimolar amounts of $99.9 \%$ pure gallium and indium metals were placed into the graphite cell that ensured reducing conditions for the possible presence of oxides contaminants.

The ions observed were $\mathrm{Ga}^{+}, \mathrm{In}^{+}, \mathrm{Ga}_{2}^{+}, \mathrm{In}_{2}^{+}, \mathrm{GaIn}^{+}$. Their identification as parent ions was accomplished as usual by measurement of mass-to-charge ratios, isotopic abundances, shutter profiles, and ionization efficiency curves (IEC). Their appearance potentials ( $\mathrm{AP}$, in $\mathrm{eV}$ ) obtained by the linear extrapolation of the IEC's were $6.0 \pm 0.5,5.8$ $\pm 0.5,6.2 \pm 0.5$, and $6.0 \pm 0.5$, respectively. The AP values for $\mathrm{Ga}_{2}^{+}$and $\mathrm{In}_{2}^{+}$agree remarkably with previous measurements ${ }^{3,6}$ and theoretical evaluation, ${ }^{1}$ while for $\mathrm{GaIn}^{+}$ the value here measured represents a first determination. Peaks corresponding to $\mathrm{Ga}_{2} \mathrm{O}^{+}$were also observed in the initial runs, the intensity of which was lower than the intensities of the metal ions and decreased along the vaporization experiment. The intensities of the metal ions utilized in the equilibria were taken when the intensity of $\mathrm{Ga}_{2} \mathrm{O}^{+}$was sufficiently low to avoid a possible contribution to the measured intensity of $\mathrm{Ga}_{2}^{+}$coming from its fragmentation indication of which, on the other hand, was not given by inspection of the IECs.

The measured ion currents are listed in Table I. The intensities measured for the various ions were converted into partial pressures by the well known relation $P_{i}$ $=K \cdot f_{i} \cdot I_{i}^{+} \cdot T$, where $K$ is the instrumental constant and the 
TABLE I. Measured ion currents, in A, over the Ga-In system.

\begin{tabular}{|c|c|c|c|c|c|c|}
\hline \multirow[b]{2}{*}{$\operatorname{Run}^{\mathrm{a}}$} & \multirow[b]{2}{*}{$T / \mathrm{K}$} & \multicolumn{5}{|c|}{ Ion intensities } \\
\hline & & ${ }^{69} \mathrm{Ga}$ & ${ }^{115}$ In & ${ }^{140} \mathrm{Ga}_{2}$ & ${ }^{230} \mathrm{In}_{2}$ & ${ }^{184} \mathrm{GaIn}$ \\
\hline \multirow[t]{10}{*}{ MS1 } & 1465 & $1.17 e-07$ & $3.00 e-07$ & & & $1.00 e-11$ \\
\hline & 1468 & $1.20 e-07$ & $3.00 e-07$ & $2.50 e-11$ & $5.19 e-12$ & $9.00 e-12$ \\
\hline & 1502 & $2.13 e-07$ & $4.40 e-07$ & $2.50 e-11$ & $8.50 e-12$ & \\
\hline & 1470 & $8.40 e-08$ & $1.59 e-07$ & & $2.00 e-12$ & \\
\hline & 1531 & $2.13 e-07$ & $3.10 e-07$ & $2.40 e-11$ & $4.72 e-12$ & \\
\hline & 1582 & $5.00 e-07$ & $4.00 e-07$ & $1.02 e-10$ & $6.20 e-12$ & $3.60 e-11$ \\
\hline & 1517 & $3.10 e-07$ & $1.77 e-07$ & $4.50 e-11$ & $1.89 e-12$ & $1.30 e-11$ \\
\hline & 1464 & $1.32 e-07$ & $9.30 e-08$ & $1.10 e-11$ & & $4.00 \mathrm{e}-12$ \\
\hline & 1596 & $7.50 e-07$ & $2.50 e-07$ & $1.53 e-10$ & $3.50 e-12$ & $3.00 e-11$ \\
\hline & 1587 & $7.60 e-07$ & $2.04 e-07$ & $1.68 e-10$ & & $2.40 e-11$ \\
\hline \multirow[t]{11}{*}{ MS2 } & 1446 & $6.10 e-08$ & $4.70 e-07$ & $3.00 e-12$ & $1.80 e-11$ & $1.10 e-11$ \\
\hline & 1452 & $6.10 e-08$ & $4.50 e-07$ & $3.00 e-12$ & $2.10 e-11$ & \\
\hline & 1501 & $1.29 e-07$ & $8.20 e-07$ & $1.30 e-11$ & $5.10 e-11$ & $3.20 e-11$ \\
\hline & 1501 & $1.38 e-07$ & $7.90 e-07$ & $1.30 e-11$ & $4.20 e-11$ & $3.30 e-11$ \\
\hline & 1558 & $3.02 e-07$ & $1.43 e-06$ & $4.56 e-11$ & $1.08 e-10$ & $8.55 e-11$ \\
\hline & 1505 & $1.71 e-07$ & $5.70 e-07$ & $1.70 e-11$ & $2.40 e-11$ & $2.70 e-11$ \\
\hline & 1470 & $1.11 e-07$ & $3.30 e-07$ & $9.00 e-12$ & $1.00 e-11$ & $1.00 e-11$ \\
\hline & 1531 & $2.70 e-07$ & $5.70 e-07$ & $3.60 e-11$ & $1.80 e-11$ & $3.30 e-11$ \\
\hline & 1583 & $4.94 e-07$ & $5.00 e-07$ & $1.03 e-10$ & $1.50 e-11$ & $4.75 e-11$ \\
\hline & 1632 & $9.31 e-07$ & $3.80 e-07$ & $2.85 e-10$ & $7.50 e-12$ & $5.70 e-11$ \\
\hline & 1596 & $5.13 e-07$ & $1.14 e-07$ & $1.03 e-10$ & & $1.14 e-11$ \\
\hline \multirow[t]{10}{*}{ MS3 } & 1482 & $2.40 e-08$ & $4.50 e-07$ & & $4.90 e-11$ & $9.00 e-12$ \\
\hline & 1525 & $4.10 e-08$ & $7.20 e-07$ & $4.20 e-12$ & $9.30 e-11$ & $2.10 e-11$ \\
\hline & 1556 & $6.00 e-08$ & $8.34 e-07$ & $6.00 e-12$ & $1.14 e-10$ & $3.80 e-11$ \\
\hline & 1604 & $1.20 e-07$ & $1.12 e-06$ & $2.10 e-11$ & $1.86 e-10$ & $7.20 e-11$ \\
\hline & 1640 & $2.16 e-07$ & $1.10 e-06$ & $5.40 e-11$ & & $1.02 e-10$ \\
\hline & 1642 & $2.80 e-07$ & $7.10 e-07$ & $6.90 e-11$ & $6.60 e-11$ & \\
\hline & 1605 & $2.20 e-07$ & $2.10 e-07$ & $4.50 e-11$ & $6.50 e-12$ & $2.30 e-11$ \\
\hline & 1603 & $2.30 e-07$ & $1.10 e-07$ & & & $1.30 e-11$ \\
\hline & 1573 & $1.65 e-07$ & $4.80 e-08$ & & & $5.00 e-12$ \\
\hline & 1571 & $1.74 e-07$ & $3.00 e-08$ & & & $4.00 e-12$ \\
\hline
\end{tabular}

${ }^{\mathrm{a}} \mathrm{K}\left(\right.$ in $\left.\operatorname{atm~} \mathrm{A}^{-1} \mathrm{~K}^{-1}\right)=0.463,0.513$, and 1.737 for runs MS1, MS2 and MS3, respectively.

factor $f_{i}=1 / \sigma_{i} \cdot \gamma_{i} \cdot a_{i}$ includes the cross section, multiplier gain, and isotopic abundance of the specific ion.

The instrument sensitivity constants $K$, reported as a footnote in Table I, were evaluated both by repeated quantitative silver calibration vaporizations and through checks of the equilibrium $\mathrm{Ga}_{2}(g)=2 \mathrm{Ga}(g)$ by adopting the relevant data of Shim et al. ${ }^{3}$ The results of the two procedures agreed within $20 \%$. The ionization cross sections for the atoms were taken from Mann ${ }^{7}$ while for the biatomic species they were assumed as 0.75 times the sum of the cross sections of the constituent atoms, a prevailing choice adopted in literature. The multiplier gains were assumed to be proportional to the inverse square root of the relevant ionic masses. The specific factors $f_{i}$ adopted are 2.325, 1.654, 2.770, 1.138, and 2.233 for $\mathrm{Ga}, \mathrm{In}, \mathrm{Ga}_{2}, \mathrm{In}_{2}$ and $\mathrm{GaIn}$, respectively.

\section{B. Reaction enthalpies and dissociation energies}

The here identified and studied GaIn molecule represents a first example of heteronuclear diatomic species of the intergroup IIIA for which the bond strength has been measured. Actually, the only indirect indication for the possible presence of a species $\mathrm{Ga}_{x} \mathrm{In}_{x}$ or $\mathrm{Ga}_{x} \mathrm{In}_{x} \mathrm{H}$ was previously inferred by Ginter et al. ${ }^{8}$ from the features of the emission spectrum obtained by vaporizing a mixture of $\mathrm{Ga}$ and In metals in a King furnace. However, no assignment and mo- lecular constants were given. In the present study the dissociation energy of gaseous GaIn was obtained from the thermochemical study of the gas-phase direct dissociation reaction,

$$
\mathrm{GaIn}=\mathrm{Ga}+\mathrm{In}
$$

and of the isomolecular exchange reactions,

$$
\begin{aligned}
& \mathrm{GaIn}+\mathrm{Ga}=\mathrm{Ga}_{2}+\mathrm{In}, \\
& \mathrm{GaIn}+\mathrm{In}=\mathrm{In}_{2}+\mathrm{Ga}, \\
& 2 \mathrm{GaIn}=\mathrm{Ga}_{2}+\mathrm{In}_{2},
\end{aligned}
$$

involving the dimers $\mathrm{Ga}_{2}$ and $\mathrm{In}_{2}$ for which the dissociation energy values, although reported in literature, were here redetermined from the reactions

$$
\mathrm{Ga}_{2}=2 \mathrm{Ga}
$$

and

$$
\mathrm{In}_{2}=2 \mathrm{In} .
$$

Rigorously, reactions (2), (3), and (4) should not be considered as completely independent being obtainable by combinations of reactions (1), (5), and (6). Actually they were retained in the overall analysis in order to take into account the different influence of the experimental points in each 
TABLE II. Summary of all-gas reactions enthalpies and derived dissociation energies.

\begin{tabular}{|c|c|c|c|c|c|c|}
\hline \multirow[b]{2}{*}{ Reaction } & \multirow[b]{2}{*}{$\begin{array}{l}\text { No. } \\
\text { points }\end{array}$} & \multicolumn{2}{|c|}{ Second-law } & \multicolumn{2}{|c|}{ Third-law } & \multirow[b]{2}{*}{$\begin{array}{l}\Delta H_{0 \text { selected }}^{0} \\
\mathrm{~kJ} \mathrm{~mol}^{-1}\end{array}$} \\
\hline & & \multicolumn{2}{|c|}{$\mathrm{kJ} \mathrm{mol}^{-1}$} & $\begin{array}{c}\Delta H_{0}^{0} \\
\mathrm{~kJ} \mathrm{~mol}^{-1}\end{array}$ & $\begin{array}{c}\operatorname{trend}^{\mathrm{a}} \\
\mathrm{J} \mathrm{mol}^{-1} \mathrm{~K}^{-1}\end{array}$ & \\
\hline $\mathrm{GaIn}=\mathrm{Ga}+\mathrm{In}$ & 26 & $104.8 \pm 7.0$ & $92.8 \pm 7.0$ & $87.3 \pm 1.3$ & 3.7 & $90.1 \pm 3.6$ \\
\hline $\mathrm{GaIn}+\mathrm{Ga}=\mathrm{Ga}_{2}+\mathrm{In}$ & 21 & $-15.2 \pm 14.0$ & $-13.0 \pm 14.0$ & $-23.9 \pm 2.3$ & 4.8 & $-18.5 \pm 7.0$ \\
\hline $\mathrm{GaIn}+\mathrm{In}=\mathrm{In}_{2}+\mathrm{Ga}$ & 18 & $22.0 \pm 12.9$ & $19.3 \pm 12.9$ & $15.2 \pm 1.8$ & 3.2 & $17.3 \pm 6.5$ \\
\hline $\mathrm{GaIn}=\mathrm{Ga}_{2}+\mathrm{In}_{2}$ & 17 & $-0.6 \pm 19.7$ & $-1.1 \pm 19.7$ & $-8.8 \pm 2.7$ & 3.0 & $-5.0 \pm 9.9$ \\
\hline $\mathrm{Ga}_{2}=2 \mathrm{Ga}$ & 25 & $124.5 \pm 9.6$ & $110.4 \pm 9.6$ & $111.2 \pm 1.8$ & 1.9 & $110.8 \pm 4.9$ \\
\hline $\mathrm{In}_{2}=2 \mathrm{In}$ & 22 & $85.9 \pm 11.2$ & $76.7 \pm 11.2$ & $72.0 \pm 1.9$ & 2.2 & $74.4 \pm 5.7$ \\
\hline
\end{tabular}

${ }^{\mathrm{a}}$ Here the trend is the temperature coefficient of an assumed linear dependence of the calculated third-law $\Delta H_{0}^{0}$ vs $T$. Absolute values are reported.

individual reaction. In essence, for the determination of the dissociation energy of GaIn reactions (1) and (2) were preferentially utilized while reactions (3) and (4) were used as further check for the consistency of the results.

The enthalpy changes, $\Delta H_{0}^{0}$ for reactions (1)-(6) were calculated from the equilibrium data both by the second-law method (based on least-squares analysis of $\ln K$ vs $1 / T$ plots) and the third-law method-\{based on $\Delta H_{0}^{0}=-R T \ln K p$ $\left.-T \Delta\left[\left(G_{T}^{0}-H_{0}^{0}\right) / T\right]\right\}$. The thermal functions Gibbs energy function $(\mathrm{Gef}),-\left(G_{T}^{0}-H_{0}^{0}\right) / T$, and heat content function, $\left(H_{T}^{0}-H_{0}^{0}\right)$, for atomic gallium and indium were taken from Hultgren et al., ${ }^{9}$ while for the biatomic species they were evaluated as described in subsequent section.

In Table II is reported a summary of the second-law and third-law analyses of the equilibrium data. The derived dissociation energies are discussed later in the text.

\section{Thermal functions}

\section{1. $G a_{2}$}

Shim et al. ${ }^{3}$ calculated the thermal functions of diatomic gallium using the harmonic oscillator-rigid rotator approximation. The molecular constants were $R_{e}=0.272 \mathrm{~nm}, \omega_{e}$ $=180 \mathrm{~cm}^{-1}$. The evaluation was made including in the calculation of the electronic contribution a number of calculated low-lying electronic states. In the course of the present study we re-evaluated the thermal functions of $\mathrm{Ga}_{2}$ using the set of molecular constants calculated by Balasubramanian ${ }^{1}$ for each of the low-lying electronic states (see Table III in Ref. 1). As the two sets of thermal functions values agree within the uncertainties, the difference being, at $1600 \mathrm{~K}, 0.9 \mathrm{~J}$ $\mathrm{K}^{-1} \mathrm{~mol}^{-1}$ in the Gef and $0.7 \mathrm{~kJ} \mathrm{~mol}^{-1}$ in the heat-content function, respectively, we have used the thermal functions already calculated by Shim et al. ${ }^{3}$

\section{2. $\ln _{2}$}

Both the two theoretical investigations carried out by Balasubramanian and $\mathrm{Li}^{10}$ and Igel-Mann et al. ${ }^{11}$ agree in finding the ${ }^{3} \Pi$ state to be the ground state for $\operatorname{In}_{2}$. In the evaluation of the thermal functions we utilized the relativistic results of Balasubramanian and $\mathrm{Li}^{10}$ where the electronic levels including the $\omega-\omega$ coupling are provided. The first ten reported electronic levels were taken into account. This leads to calculate thermal functions noticeably different from those evaluated by De Maria et $a l^{6}{ }^{6}$ on the basis of molecular pa- rameters estimated as ${ }^{1} \Sigma$ electronic ground state, $R_{e}$ $=0.30 \mathrm{~nm}$, and $\omega_{e}=135 \mathrm{~cm}^{-1}$. In particular, our Gef and heat-content values calculated at $1600 \mathrm{~K}$ differ by +13 $\mathrm{J} \mathrm{K}^{-1} \mathrm{~mol}^{-1}$ and $+9 \mathrm{~kJ} \mathrm{~mol}^{-1}$, respectively.

\section{Galn}

For GaIn the translational and internal contribution to the thermal functions were computed separately. In lack of any theoretical and experimental data for the electronic levels and molecular parameters the contribution of the internal motions has been interpolated from those of $\mathrm{Ga}_{2}$ and $\mathrm{In}_{2}$ calculated with the parameters given by Balasubramanian ${ }^{1,10}$ by correcting for the rotational term due to the different symmetry number for the homonuclear and heteronuclear species. The calculated thermal functions for $\mathrm{In}_{2}$ and GaIn are reported in Table III.

\section{DISCUSSION}

Let us first discuss the results for the homonuclear diatomics $\mathrm{Ga}_{2}$ and $\mathrm{In}_{2}$.

\section{A. $\mathrm{Ga}_{2}$}

The dissociation energy of diatomic gallium is relatively well known. Two recent studies, one theoretical by Balasubramanian $^{1}$ and the other experimental and theoretical by Shim et al. ${ }^{3}$ give for $D_{0}^{0}\left(\mathrm{Ga}_{2}\right)$ the values $115.8 \mathrm{~kJ} \mathrm{~mol}^{-1}$ and $110.3 \pm 7.0 \mathrm{~kJ} \mathrm{~mol}^{-1}$, respectively. Earlier KC-MS investigations ${ }^{12-14}$ indicate much larger values ranging from 135 to $145 \mathrm{~kJ} \mathrm{~mol}^{-1}$ which essentially represent upper limits.

TABLE III. Gibbs energy functions, $-\left(G_{T}^{0}-H_{0}^{0}\right) / T$, in $\mathrm{J} \mathrm{K}^{-1} \mathrm{~mol}^{-1}$, and heat content functions, $\left(H_{T}^{0}-H_{0}^{0}\right)$, in $\mathrm{kJ} \mathrm{mol}^{-1}$, for $\operatorname{In}_{2}(g)$ and $\operatorname{GaIn}(g)$.

\begin{tabular}{cccccc}
\hline \hline & \multicolumn{2}{c}{$\operatorname{In}_{2}$} & & \multicolumn{2}{c}{ GaIn } \\
\cline { 2 - 3 } \cline { 5 - 6 }$T / \mathrm{K}$ & $-\left(G_{T}^{0}-H_{0}^{0}\right) / T$ & $\left(H_{T}^{0}-H_{0}^{0}\right)$ & & $-\left(G_{T}^{0}-H_{0}^{0}\right) / T$ & $\left(H_{T}^{0}-H_{0}^{0}\right)$ \\
\hline 298.15 & 233.92 & 11.72 & & 238.94 & 11.13 \\
1100 & 287.87 & 46.58 & & 289.88 & 43.97 \\
1200 & 291.55 & 50.82 & & 293.86 & 48.03 \\
1300 & 294.94 & 55.05 & & 296.57 & 52.10 \\
1400 & 298.08 & 59.27 & & 299.54 & 56.17 \\
1500 & 301.00 & 63.48 & & 302.31 & 60.26 \\
1600 & 303.73 & 67.70 & 304.91 & 64.36 \\
1700 & 306.30 & 71.92 & 307.34 & 68.47 \\
1800 & 308.72 & 76.15 & 309.65 & 72.58 \\
\hline \hline
\end{tabular}


The present determination, based on 25 data points, gives a second-law $\Delta H_{0}^{0}=110.4 \pm 9.6 \mathrm{~kJ} \mathrm{~mol}^{-1}$ and a third-law $\Delta H_{0}^{0}=111.2 \pm 1.8 \mathrm{~kJ} \mathrm{~mol}^{-1}$. The average value, 110.8 $\pm 4.9 \mathrm{~kJ} \mathrm{~mol}^{-1}$, is in agreement with the result of Shim et al., ${ }^{3}$ and also confirms the value calculated by Balasubramanian. ${ }^{1}$

\section{B. $\ln _{2}$}

The value of the dissociation energy of indium dimer is still controversial. Published values are scarce and spread from 80 to $102 \mathrm{~kJ} \mathrm{~mol}^{-1}$. Among the experimental values, all based on early mass spectrometric investigations, ${ }^{6,12,14}$ apparently only the study by De Maria et al., ${ }^{6}$ who quoted $D_{0}^{0}$ $\left(\mathrm{In}_{2}\right)=93.7 \mathrm{~kJ} \mathrm{~mol}^{-1}$, is fully reliable as concerns quality and number of data points. Drowart and Honig ${ }^{12}$ estimated an upper limit of $96.5 \mathrm{~kJ} \mathrm{~mol}^{-1}$ while the value $102.5 \mathrm{~kJ} \mathrm{~mol}^{-1}$ reported by Gingerich and Blue ${ }^{14}$ is based on a preliminary experiment. Froben et al., ${ }^{15}$ on the basis of Raman spectra of matrix-isolated group IIIA dimers, reported a ${ }^{3} \Sigma^{-}$ground state and $\omega_{e}=118 \mathrm{~cm}^{-1}$ and as a consequence the dissociation energy quoted by Huber and Herzberg ${ }^{4}\left(1.0_{1} \mathrm{eV}\right)$ was corrected to $0.87 \mathrm{eV}$ or $84 \mathrm{~kJ} \mathrm{~mol}^{-1}$. More recently, the theoretical investigations carried out by Balasubramanian and $\mathrm{Li}^{10}$ and Igel-Mann et al. ${ }^{11}$ agree, as mentioned above, in quoting a ${ }^{3} \Pi$ ground state and in the corresponding $D_{e}$ values (1.02 and $1.09 \mathrm{eV}$, respectively). Balasubramanian and $\mathrm{Li}^{10}{ }^{10}$ on the other hand, found the spin-orbit effect to be non-negligible for the electronic states of $\mathrm{In}_{2}$. By inclusion of this effect they ultimately propose a ${ }^{3} \Pi_{u}\left(O_{u}^{-}\right)$ground state with a $D_{e}$ of $0.83 \mathrm{eV}$ or $80 \mathrm{~kJ} \mathrm{~mol}^{-1}$. Such spread of values merits a discussion of the reliability of the experimental results obtained so far. The higher experimental value of De Maria et al. ${ }^{6}$ is probably overestimated partly as a consequence of uncorrect assumptions for the molecular parameters of $\operatorname{In}_{2}$ used in the estimation of the thermal functions. In our experiments we determined a dissociation energy value slightly lower than the Balasubramanian-Li theoretical value. ${ }^{10}$ The second-law $(0 \mathrm{~K})$ dissociation enthalpy, $\Delta H_{0}^{0}$ $=76.7 \pm 11.2 \mathrm{~kJ} \mathrm{~mol}^{-1}$, agrees within the quoted uncertainties with the average third-law value, $\Delta H_{0}^{0}=72.0$ $\pm 1.9 \mathrm{~kJ} \mathrm{~mol}^{-1}$. In view of the small temperature trend $\left(-2.2 \mathrm{~J} \mathrm{~K}^{-1} \mathrm{~mol}^{-1}\right)$ of the individual third-law $\Delta H_{0}^{0} \mathrm{~s}$, we propose for the dissociation energy of $\mathrm{In}_{2}$ the average between second-law and third-law results, namely, 74.4 $\pm 5.7 \mathrm{~kJ} \mathrm{~mol}^{-1}$. Considered the relatively high number of experimental data points and the modern spectroscopic constants employed in the calculation of the thermal functions of $\mathrm{In}_{2}$, this value has been adopted as reference for checking the dissociation enthalpy of GaIn through the study of the exchange isomolecular equilibria.

However, it is interesting to compare the results of the present study with those of De Maria et al. ${ }^{6}$ who quote a $\Delta H_{0}^{0}$ (In-In) $19 \mathrm{~kJ}$ higher than our selected value. As mentioned above this discrepancy apparently comes primarily from the substantial difference in the adopted molecular constants and the thermal functions calculated therefrom for $\mathrm{In}_{2}$ in the two cases. A reanalysis of the mass spectrometric data points of De Maria et al. ${ }^{6}$ with use of our thermal functions rises the second-law enthalpy by about $7 \mathrm{~kJ} \mathrm{~mol}^{-1}$ and lowers the third-law enthalpy by about $17 \mathrm{~kJ} \mathrm{~mol}^{-1}$, which would bring to a disagreement between their second-law and third-law of about $21 \mathrm{~kJ} \mathrm{~mol}^{-1}$ and a marked trend in the third-law values.

A part the differences discussed above in the thermal functions estimates, the disagreement between the more experimentally direct second-law values, even if the two experimental studies were carried out in different temperature and pressure ranges and on different chemical systems, should not be readily dismissed. Therefore, in our opinion, the value of the bond strength of indium dimer would merit further experimental investigation with an independent technique. At present, however, the dissociation energy here measured definitely supports the theoretical results of Balasubramanian and $\mathrm{Li}^{10}{ }^{10}$ based on a non-negligible spin-orbit interaction effect.

\section{Galn}

As anticipated, the determination of the dissociation energy of GaIn relied on the measurement of the equilibrium constants of the direct dissociation reaction (1) and of the exchange reaction (2) preferred to reaction (3) as it involves the molecule $\mathrm{Ga}_{2}$ which, in our opinion, is much better experimentally characterized. Reaction (1), although dependent on the sensitivity constant of the mass spectrometer, involves the measurement of the species $\mathrm{Ga}^{+}$and $\mathrm{In}^{+}$of high intensity and so less subjected to gross experimental errors. The other isomolecular reactions (3) and (4) were utilized as further check of the dissociation energy of GaIn.

The second-law and third-law values for the dissociation reaction (1), $92.8 \pm 7.0 \mathrm{~kJ} \mathrm{~mol}^{-1}$ and $87.3 \pm 1.3 \mathrm{~kJ} \mathrm{~mol}^{-1}$, respectively, agree within the reported uncertainties and therefore we selected the average value $\Delta H_{0,1}^{0}(\mathrm{Ga}-\mathrm{In})=90.1$ $\pm 3.6 \mathrm{~kJ} \mathrm{~mol}^{-1}$. For the isomolecular exchange reaction (2) the second-law and third-law analyses of the equilibrium data yield $\Delta H_{0,2}^{0}=-13.0 \pm 14.0 \mathrm{~kJ} \mathrm{~mol}^{-1}$ and $-23.9 \pm 2.3$ $\mathrm{kJ} \mathrm{mol}^{-1}$, respectively. Here again, we selected the average value, $\Delta H_{0,2}^{0}=-18.5 \pm 7.0 \mathrm{~kJ} \mathrm{~mol}^{-1}$ which has been combined with the value here adopted for the dissociation energy of $\mathrm{Ga}_{2}$ to obtain the dissociation enthalpy $\Delta H_{0,2}^{0}$ $(\mathrm{Ga}-\mathrm{In})=91.8 \pm 9.9 \mathrm{kmol}^{-1}$, in agreement with the result of reaction (1).

As concerns reactions (3) and (4), their enthalpies, $\Delta H_{0,3}^{0}=17.3 \pm 6.5 \mathrm{~kJ} \mathrm{~mol}^{-1}$ and $\Delta H_{0,4}^{0}=-5.0 \pm 9.9 \mathrm{~kJ} \mathrm{~mol}^{-1}$ selected as averages of the second-law and third-law values, when combined with the dissociation energies of $\mathrm{Ga}_{2}$ and $\mathrm{In}_{2}$ lead, respectively, to $\Delta H_{0,3}^{0}(\mathrm{Ga}-\mathrm{In})=91.7 \pm 8.6 \mathrm{~kJ} \mathrm{~mol}^{-1}$ and $\Delta H_{0,4}^{0}(\mathrm{Ga}-\mathrm{In})=89.9 \pm 6.7 \mathrm{~kJ} \mathrm{~mol}^{-1}$ which well reproduce the results obtained from use of reactions (1) and (2).

In conclusion, on the basis of the enthalpies of the various all-gas reactions, by giving to the direct reaction (1) a weight two in respect to the exchange reaction (2), we propose for the dissociation energy of the GaIn molecule the value $\Delta H_{0}^{0}(\mathrm{Ga}-\mathrm{In})=90.7 \pm 3.7 \mathrm{~kJ} \mathrm{~mol}^{-1}$. 
${ }^{1}$ K. Balasubramanian, J. Phys. Chem. 94, 7764 (1990), and references cited therein.

${ }^{2}$ K. Balasubramanian, Chem. Rev. 90, 93 (1990), and references cited therein.

${ }^{3}$ I. Shim, K. Mandix, and K. A. Gingerich, J. Phys. Chem. 95, 5435 (1991).

${ }^{4}$ See (a) K. P. Huber and G. Herzberg, Molecular Spectra and Molecular Structure IV. Constants of Diatomic Molecules (Van Nostrand Reinhold, New York, 1979); (b) A. R. Miedema and K. A. Gingerich, J. Phys. B 12, 2081 (1979); 12, 2255 (1979); L. Brewer and J. S. Gwynn, Faraday Symp. Chem. Soc. 14, 136 (1980).

${ }^{5}$ (a) G. Balducci, P. E. Di Nunzio, G. Gigli, and M. Guido, J. Chem. Phys. 90, 406 (1989); (b) R. T. Grimes, in The Characterization of High Temperature Vapors, edited by J. L. Margave (Wiley, New York, 1967), p. 195.

${ }^{6}$ G. De Maria, J. Drowart, and M. G. Inghram, J. Chem. Phys. 31, 1076 (1959).

${ }^{7}$ J. B. Mann, in Recent Developments in Mass Spectroscopy, edited by K.
Ogata and T. Hayakawa (University Park, Tokyo, 1980), p. 81.

${ }^{8}$ D. S. Ginter, M. L. Ginter, and K. K. Innes, J. Phys. Chem. 69, 2480 (1965).

${ }^{9}$ R. Hultgren, P. J. Desai, D. T. Hawkins, M. Gleiser, K. K. Kelley, and D. D. Wagman, Selected Values of Thermodynamic Properties of the Elements (American Society for Metals, Metals Park, 1973).

${ }^{10}$ K. Balasubramanian and J. Li, J. Chem. Phys. 88, 4979 (1988).

${ }^{11}$ G. Igel-Mann, C. Feller, H.-J. Flad, A. Savin, H. Stoll, and H. Preuss, Mol. Phys. 68, 209 (1989).

${ }^{12}$ J. Drowart and R. E. Honig, J. Phys. Chem. 61, 980 (1957).

${ }^{13}$ W. Chupka, J. Berkowitz, C. F. Giese, and M. G. Inghram, J. Phys. Chem. 63, 611 (1958).

${ }^{14}$ K. A. Gingerich and G. D. Blue, 18th Annual Conference on Mass Spectrometry and Allied Topics, San Francisco, California, 1970.

${ }^{15}$ F. W. Froben, W. Schulze, and U. Kloss, Chem. Phys. Lett. 99, 500 (1983). 
The Journal of Chemical Physics is copyrighted by the American Institute of Physics (AIP). Redistribution of journal material is subject to the AIP online journal license and/or AIP copyright. For more information, see http://ojps.aip.org/jcpo/jcpcr/jsp 